\title{
Providing Assistive Technology Training to a Rural School of Education Through an In-Direct Service Strategy
}

\author{
Melissa Salem Darrow \\ W. Scott Thomson \\ School of Education, East Carolina University \\ Greenville, NC 27858 USA
}

\begin{abstract}
A strategy is described for staffing and equipping an assistive technology training laboratory within the constraints of a rural environment. The acquisition of appropriate hardware and peripherals is described, as well as a model for staff training and the coincidental delivery of service to a disabled population. A discussion of the effectiveness of the project is included.
\end{abstract}

\section{Introduction}

The use of microcomputers and other generic technologies equipped with specialized adaptive peripheral devices is revolutionizing the education of students with disabilities. Through the use of the growing array of available systems, persons with sensory, physical, and/or intellectual disabilities can achieve previously unobtainable levels of personal independence and freedom. As these technologies become increasingly available in public schools and residential programs serving children and youth with disabilities, special educators are expected to demonstrate competencies required to use them effectively. Increasingly, even regular classroom teachers are expected to enter their profession armed with the knowledge and skills necessary to provide children with disabilities full access to the educational experiences other children enjoy. In today's schools, meeting this expectation often includes demonstrating competency in the use of adaptive technology.

Specifically, educators and related service personnel need skills in the following areas: (a) assessment of students in order to provide the appropriate peripheral match for physical and/or cognitive needs; (b) selecting peripherals in relation to specific types of applications such as environmental control, vocational needs, leisure/recreation or cause and effect training; (c) interfacing peripherals with the computer; (d) customizing the specific function of the peripherals to meet individual student needs; (e) accessing electronic augmentative communication devices that utilize microcomputer technology; and (f) advocating for students in relation to procuring devices and effectively integrating them into students' environments [1,2, $3,4]$.

In 1991, the East Carolina University Special Education Department applied for, and obtained, internal funding to support a small Assistive Technology Laboratory to be housed within the School of Education. Prior to its inception, there was no access to equipment or software needed to adequately train educators to specialized technology with individuals with disabilities. The Department of Special Education had acquired limited samples of adaptive devices and a small quantity of software, in 
addition to video tapes demonstrating uses of technologies to which there was no access for hands-on practice. The existing collection proved to be grossly inadequate for addressing the training needs of over 249 graduate and undergraduate special education majors, as well as the other 1,713 students majoring in elementary and secondary teacher and administrator preparation programs, who also sought this important knowledge and training. Once funding became available, a limited set of equipment and software was purchased, a small staff was assembled and trained, and purposes of the laboratory were outlined.

\section{Method}

Discussion of the methods for using the Assistive Technology Laboratory necessary includes descriptions of equipment and software that was purchased, purposes defined for the laboratory, and the staffing methods that were used. Of particular interest was a volunteer training project that began as a method of addressing staffing needs and has since become one of the core purposes of the laboratory.

\subsection{Physical Description of the Assistive Technology Laboratory}

Hardware. Two IBM DOS ${ }^{\mathrm{TM}}$ platform machines, two Apple G S $S^{\mathrm{TM}}$ and 1 Macintosh LC II TM were purchased. In order to make the computers accessible to the special needs of a wide variety of children and youth, a full array of adaptive devices was added to each machine. Each "prototype station" was equipped with specialized peripheral appliances, which included Touch Windows TM, Muppet Learning Keys ${ }^{T M}$, Power Pads ${ }^{T} M$, Intellikeys ${ }^{T M}$, Unicorn Expanded Keyboards ${ }^{\mathrm{TM}}$, Speech Synthesizers and single switches. The intent was to represent as many as possible of the types of machines and peripheral devices that teachers might encounter in school settings. The five stations were placed within a wheelchair accessible environment, central to the School of Education.

Software. An emerging variety of specialized software is devoted to the needs of special education populations. This software is equally useful for use by the regular student population, due to its tendency to break down complex tasks into more easily learned linear sequences. A representative sample of this software was purchased that represented the needs of students with mild to severe cognitive limitations, learning disabilities, sensory impairments and physical disabilities. The most difficult disability to address specifically with currently available software appears to be behavior disorders. All curriculum domains were represented by the approximately 250 software packages purchased, including personal/social skills, vocational skills, language arts, leisure and recreation, cause and effect, and so on. Additionally, the software was selected to serve students across age categories so that software for students from birth through adult could be represented.

Goals of the Laboratory. It became evident from the outset that before any activities or training could begin in the Laboratory, it would be necessary to define some very specific purposes of its use. These simply defined goals became a blueprint for all laboratory activities. The goals were also set into a prioritized order, according to importance, so that later the staff were able to prioritize projects and activities according to this order. Five prioritized goals were defined, as follows. 
Goal 1: Develop special education majors' competency in the use of technology with exceptional children and facilitate the use of appropriate software and hardware in departmental courses and practica.

Goal 2: Provide training to undergraduate and graduate students from other departments in the School of Education in the use of adaptive computer systems with students who have disabilities.

Goal 3: Provide computer access to students with disabilities attending East Carolina University.

Goal 4: Secure external funding for technology-related projects.

Goal 5: Provide a community resource for persons seeking information on assistive technologies.

Staffing. The staff was composed of graduate research assistants and a professor in the ECU Department of Special Education. When students came to use the lab in groups, classroom teachers and assistants (or sometimes parents) remained in the lab with visiting students, and participated in service delivery. This allowed the laboratory staff to provide direct service, in the form of evaluation and one-on-one remediation on the appropriate hardware/software combination. At the same time, it allowed teachers and/or parents to preview software and adapt software and hardware respective to each child's individual needs.

Although the lab staff were capable, innovative and enthusiastic about their work, there were obstacles due to the lack of time that could be devoted to actual laboratory management, including individual. One issue was the lack of a full-time Director. This meant that all lab activities, including purchasing, set-up and maintenance of equipment, had to be accomplished during the "spare time" of responsible faculty members. The other staff members were either graduate students in the School of Education or undergraduate, student workers - all employed on a temporary basis. We began to realize that there would have to be a system in place that would train special education teachers in use of assistive technology while providing the children and youth visiting the lab with appropriate services. With the intent of accomplishing these tasks, the volunteer training program was developed.

The Volunteer Training Program. A structure for the volunteer training program was developed by Laboratory staff. The program included a two hour intensive training commitment, an eight hour direct service provision component, documentation procedures and evaluation measures.

Volunteer students were recruited from special education as well as other teacher education courses. Classes were brought into the laboratory, and given a brief equipment/software demonstration, as well as information on how assistive technology equipment was used. Students were then given information on the new volunteer training program, and given the opportunity to enroll for one of the initial two hour training sessions, at the beginning of which they could sign up for a total of ten volunteer hours.

At the two hour training sessions, students were given contracts to sign. The use of contracts was one of the features that facilitated the volunteer program's success. Students who participated by signing contracts could receive a number of extra credit points in courses they were taking in the School of Education (this had been prearranged with course instructors). The credit was set up on an "all or nothing" basis. If they completed ten hours or more, as specified on a contract, they received a certificate that documented that they had earned a pre-determined number of extra 
credit points. If they did not complete at least the full ten hours specified in their contract, they received no points. No partial credit points were awarded.

After the contracts were signed, students received instructions on how to use the volunteer time documenting materials. After these initial business items had been addressed, the rest of their two hours was spent on intensive training time with laboratory staff on use of the assistive technology equipment and software in the laboratory that they would be using. They were each assigned to a time slot when their volunteer hours would be fulfilled, as well as a computer station, upon which they would focus their training.

All volunteers completed eight hours of work directly with students with disabilities in the lab, at an assigned station. They were not randomly assigned to students as they showed up, but instead assigned to specific times and students on a consistent basis. We felt this would increase chances of success for both teachers in training and students with disabilities.

All student volunteers documented their participation after each session. Each volunteer had a folder in which they kept an ongoing log of what had occurred during each of their volunteer sessions, along with any questions or concerns that came up. They were also asked to document any evaluative remarks on the volunteer system or the lab itself. On the same form, a member of the laboratory staff would sign to document that the volunteer had indeed completed that day's hours. This documentation system served us well, providing an ongoing description of lab activities, as well as ongoing formative and summative evaluation measures. Furthermore, this system provided a structure for students so that they could mark their progress and note their accomplishments as volunteers.

\section{Results}

\subsection{Achievement of Training Goals}

By the end of the first academic year using the Volunteer Training Program and using the Assistive Technology Laboratory, over eighty-five children and youth with special needs received direct assistive technology services in the form of evaluations and practice with equipment. Over five hundred students within the School of Education were able to experience short demonstration sessions provided by Laboratory staff. Over ten students' families used the Laboratory to find information and to try out equipment that would be most beneficial to their children.

At least twenty-five special education teachers who came to the Laboratory with their classes or individual students, or on their own, received intensive instruction on currently available assistive technology, and many were given assistance in ordering systems and software for their own classrooms, and given training in set-up, use, and maintenance of equipment.

Finally, the volunteer training program was completed by twenty-five special education and School of Education students, many of whom enjoyed the work so much that they volunteered for far more that the required ten hours. In fact, a number of volunteers who had previously selected other majors switched their majors to special education after completing the volunteer program.

Overall, the evaluation data showed that services in the Laboratory were received with high levels of satisfaction. One comment that came up repeatedly was that the Laboratory needed more equipment and more software (we have actually been able to purchase more items since that time). Additionally, Lab staff 
evaluations called for a consistent manager - a permanent staff position to coordinate all Laboratory activities. The School of Education has recently placed the attainment of this staff position high in their priorities for action for the next year.

The Laboratory was able to accomplish Goals $1,2,3$, and 5 (described in Methods, above) very successfully during its first year. The programs put into place at that time have evolved and continued, and the focus of the new Directors at this time is upon Goal 4, to obtain external funding.

\subsection{Comparisons of Hardware and Peripherals}

Computers. Of the machines purchased, the Apple II GS $\mathrm{TM}_{\text {was }}$ the most used during the first year, because of the wide array of special education peripherals and software available for that machine, at the time. The Macintosh ${ }^{\mathrm{TM}}$ slowly moved into the "most popular machine" slot over the course of the year, as more software and peripherals became available. Its "user friendly" nature and its built in capability for digitized speech made it especially useful with younger children and those with communication impairments. The IBM TM machines were probably used the least in the Assistive Technology Laboratory for two reasons. First, the adaptive peripherals that were available at the time for these two systems were extremely unreliable in terms of staying in working order. Second, because Apple Computers ${ }^{T M}$ had traditionally led educational software development while IBM ${ }^{\mathrm{TM}}$ had traditionally been a business computer, there was very little software available for use on the $\mathrm{IBM}^{\mathrm{TM}}$, and much of what was available was more easily adapted for special needs when used on one of the other systems.

Overall, across disability categories, as well as age groups, we have found the Macintosh ${ }^{\mathrm{TM}}$ systems and their accompanying adaptive peripherals to be the most versatile in terms of serving persons with a wide variety of disability types as well as a wide age range of students.

Peripherals. The Muppet Learning Keys $\mathrm{TM}_{\text {have by far been the most popular }}$ adaptive keyboards for the early childhood age range, with a wide variety of disabilities. Its digitized speech and music, as well as clear graphics when used on the Macintosh make it extremely engaging to the young learner. Additionally, it can be used with various input methods. The Touch Window ${ }^{\mathrm{TM}}$ can be used for direct selection, or even a single switch can be used for scanning selection.

For students at the elementary level, we found the Unicorn Expanded Keyboard ${ }^{\mathrm{TM}}$ as well as the Intellikeys ${ }^{\mathrm{TM}}$ to be very versatile in customizing programs for a number of curriculum areas, from basic vocabulary and communication skills to accessing word processors or mathematics programs in an alternative fashion. These peripheral devices tended to be trouble-free as far as predictability of day to day working order.

At the high school to adult levels, we werevery pleased at the adaptibility of a number of peripheral devices for persons with various types of disabilities. For example, the Intellikeys ${ }^{\mathrm{TM}}$ large, high contrast letters made it easier for a person with low vision to access a word processor, while Ke:nx ${ }^{\mathrm{TM}}$ made it possible for lab staff to customize nearly any type of conventional software for various types of selection devices, from single switch, to direct selection with the Touch Window TM. 
The Echo ${ }^{\mathrm{TM}}$ Speech Synthesizer was also a very helpful tool, across age categories, for those programs that could not be accessed using digitized speech. Unfortunately, various software packages call for various specific types of Echo $\mathrm{TM}_{\text {devices, so to }}$ be able to use it with a large number of educational programs, the user must have several versions of this peripheral device on hand. Finally, the Touch Window TM peripheral device and software became a favorite with all ages and across disability types because of its capabilities for allowing direct selection. This device was especially powerful with very young children or with persons whose cognitive or physical capability levels made use of the mouse or keyboard or scanning systems difficult or frustrating.

\section{Discussion}

This project was born out of the need to provide a great deal of equipment and services to a rural area under conditions that offered few resources. As a vehicle for magnifying the efforts of a few competent people and few resources, the authors recommend replication of the methods described above to professionals who find themselves in similar situations, with the following cautionary statement:

A weakness of the project was that what began as an indirect service project with a primary purpose of training educators gradually threatened to become a direct service resource available to the regional special education community. Any agency considering adoption of a similar plan must guard against this inherent desire of the surrounding community to convert the Laboratory to a direct service resource. This desire of the community is very understandable in an environment which has so few opportunities for similar direct services. Unchecked, such a demand necessarily forces direct service to the point where training functions become secondary.

\section{References}

1. G. Church, S. Glennen: The handbook of assistive technology. San Diego: Singular Publishing Group, Inc., 1992.

2. M. Male: Technology for inclusion: Meeting the special needs of all students. Needham Heights, Mass: Allyn and Bacon, 1994.

3. M. Darrow, J. Darrow: Preparing special educators in eastern North Carolina to use assistive technology: A multimedia approach to addressing training needs unique to rural areas. In Proceedings of the eighth annual international conference "Technology and Persons with Disabilities". Northridge, Ca: California State University, Northridge Center on Disabilities, 1993.

4. E. Jacobs: Providing assistive technology assessments for school districts: A rural model. In Proceedings of the eighth annual international conference "Technology and Persons with Disabilities". Northridge, Ca: California State University, Northridge Center on Disabilities, 1993. 